NBER WORKING PAPER SFRIES

\title{
ON TRANSACTIONS AND PRECAUTIONARY DEMAND FOR MONEY
}

Jacob A. Frenkel

Boyan Jovanovic

Worktng Paper No. 288

\author{
NATIONAL BUREAU OF ECONOMIC PESEARCH \\ 1050 Massachusetts Avenue \\ Cambr1dge MA 02138 \\ October 1978
}

The research reported here is part of the NBER's research program in International Studies. Any optnions expressed are those of the author and not those of the National Bureau of Economic Research. 


\section{Summary of \\ ON TRANSACTIONS AND PRECAUTIONARY \\ DEMAND FOR MONEY \\ by}

Jacob A. Frenke1 and Boyan Jovanovic

This paper develops a stochastic framework for the analysis of transactions and precautionary demand for money. The analyois is based on the principles of inventory managements and the key feature of the model is its stochastic characteristics which lead to the need for precautionary reserves. The formal solution for optimal money holdings is derived and is shown to depend on the rate of interest, the mean rate of net disbursements, the cost of portfollo adjustment and the variance of the stochastic process governing net disbursements. One solution is obtained by minfmizing the present value of financial management. This solution is compared with an alternative that is derived from the more conventional methodology of minfmizlng the steady-state cost function. The comparison shows that the two approaches may yleld solutions that differ signiflcantly from each other. The paper concludes with an application of the model to an empirical examination of countries' holdings of International reserves. The empirical results are shown to be consistent with the predictions of the model.

Professor Jacob A. Frenke1 Department of Economics University of ChIcago 1129 E 59th Street ChIcago, Illinois 60637 (312) $753-4516$
Boyan Jovanovic Bell Laboratories, Inc. 600 Mountain Avenue 2C 113 Murray H111, New Jersey 07974 (201) $582-4252$ 


\section{Introduction}

In this paper we develop a model of the demand for money which Incorporates transactions and precautionary motives. The analytical framework is based on the principles of inventory management which have been applied by Baumol (1952) and Tobin (1956) to study the transactions demand for money. The key feature of our model is its stochastic characteristics which lead to the need for precautionary reserves. We analyze the determinants of optimal money holdings when net disbursements are governed by a stochastic process. In this context we adopt some aspect of the analytical framework that has been developed by Miller and orr (I966).

Section II contains the analytical framework of the model and the formal derivation of optimal money holdings. In this context we analyze the determinants of the various elasticities of the demand for money. In Section III we analyze the properties of the distribution of the optimal payments period (the time spacting consecutive adjustments of money holdings), as well as the determinants of the probability that adjustment will be necessary during a given period. In Sections II and III optimal behavior is determined by minimizing the net present value of cost. In Section IV we analyze the optimal behavior from the perapective of minfmizing steady-state cost. We provide a complete characterization of the steadystate distribution and we show that optimal holdings as determined by the steadystate approach may differ signiflcantly from the optimum obtained by minimizing the net present value of cost. In Section $V$ we examine emplrically some of the predictions of the model by estimating a simple demand for international reserves. Concluding remarks are contained in Section VI. 
II. A Model of the Optimum Holdings

of Money

In this section we outline the analytical framework that is used for the derivation of the optimum holdings of money. The analytical framework Integrates transactions and precautionary motives underlying the demand for money. We start with a formal derivation.

\section{II.1 A Formal Deriviation of the Demand for Money}

Earlier studies of the transactions demand for money have emphasized the lack of synchronization between payments and receipts as the prime reason for holding an inventory of money. To highlight the transactions motive for holding money, the early formulations of Baumol (1952) and Tobin (1956) have assumed that transactions occur in a steady stream which is perfectly foreseen. In contrast with the completely deterministic nature of these mode1s, studies of the precautionary demand for money have emphasized the stochastic nature of transactions. One of the most signiflcant contributions along these lines has been made by Miller and orr (1966) who have highlighted the stochastic elements underlying the demand for money by adopting the opposite extreme assumption that net cash flows are completely stochastic. ${ }^{I}$ In what follows we analyze the determinants of optimal money holdings by incorporating varfous aspects of these two trends.

We assume that changes in money holdings can be characterized by the following stochastic equation

$$
d M(t)=-\mu d t+\sigma d W(t) ; \quad M(0)=M_{0}, \quad \mu \geq 0
$$

$1_{\text {Other studies which emphasized the stochastic nature of transactions }}$ include Olivera (1971), orr (1970), Patinkin (1965, Ch. VI); Tstang (1969) and Whalen (1966). 
where $W(t)-N(0, t)$ is the standard Wiener process that is distributed normally with mean zero and with vartance $t$, and is temporally independent. 1 In equation (1), $M_{0}$ denotes the optimal initial money holdings and $\mu$ denotes the deterministic part of net expenditures. Thus, at each point in time, the distribution of money holdings $M(t)$ is charactertzed by:

$$
\begin{aligned}
& M(t)=M_{0}-\mu t+o W(t) \text { and } \\
& M(t)-N\left(M_{0}-\mu t, \sigma^{2} t\right) .
\end{aligned}
$$

In analyzing the determinants of optinal money holdings $\mathrm{M}_{0}$, Individuals (or firms) consider two types of cost; the first belng foregone earnings on inventory holdings and the second being the cost of adjustment that has to take place once inventories have reached an undesirable lower bound. Money holders could reduce the probabiltty of having to adjust by holding a suffictently large stock of money. The costs of acquiring the higher level of security are the foregone earnings on the large inventorles of money which could have been invested In interest bearing assets. On the other hand, money holders couId reduce foregone earnings by holding a smaller stock of money, thereby raising the probability of incurring more frequertly the cost of adjusting the monetary stock to the optimal level $\mathrm{M}_{\mathrm{O}}$. The optimal level is determined by minimizing the cost of financial management where both sources of cost are taken into account. As indicated

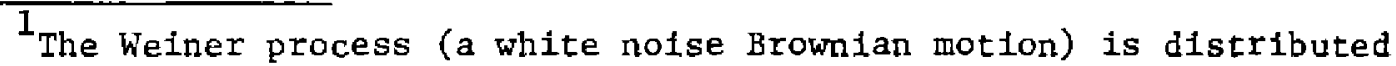
normally over any interval and is the natural limiting process for the simple random walk with independent inclements. Miller and Orr (1966) have assumed a Bernoulli process; at the limlt, when the increments and the time interval between increments approach zero, one obtains the Welner process for continuous time. This process is rather general and all diffusion processes can be represented as a functional transformation of the Weiner process. For detalls on the propertles of the process see Cox and Miller (1965) and for a slmple exposition and an application see Fischer (1975). 
above, the two sources of cost are (i) foregone earnings which depend on the rate of interest $r$ and on money holdings $M(t)$, and (1i) the cost of adjustments which is assumed to depend on the frequency of adjustment and on the fixed cost C per adjustment (e.g., "broker's fee").

It is assumed that an adjustment of the money stock 1s necessary whenever, due to the stochastic nature of net disbursement, money holdings reach a lower bound. Without loss of generality we w11l set this lower bound at zero. ${ }^{1}$ Foregone earnings and the number of times that the "broker"s fee" is being paid (1.e., the frequency of adjustments) are both random since, as is indicated in equation (2), at each point in time money holdings are random. It is assumed, therefore, that asset holders determine the optimal size of the money stock, $M_{0}$, by minlmizing the expected cost of financial management.

For analytical convenience, it is useful to separate the expected cost into the part which is incurred prior to the perlod of the first adjustment and the part that is incurred thereafter. Conslder flrst the expected foregone earnings during the period up to the date of the first adjustment. At perlod $t$, the instantaneous foregone earnings are $\mathrm{rM}(\mathrm{t})$ and thelr present value is:

$$
r M(t) e^{-r t}
$$

Let $h\left(M, t \mid M_{0}, 0\right)$ be the probability that money holdings $M(t)$ whtch at pertod zero were at the optimal level $M_{0}$, have not reached zero (the lower bound) prior

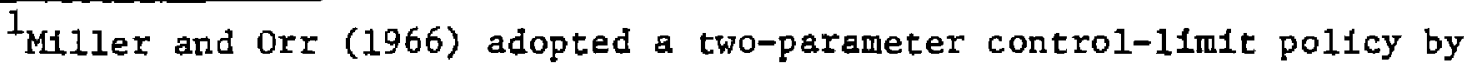
assuming that adjustment is necessary when money holdings reach a lower bound (zero) as well as when they reach an upper bound. Since their analysis is based on the steady-state distributions, and since they assume that the stochastic process is without a drift, the two bounds are necessary for the existence of the steady-state distribution. In the appendix, Miller and orr derive a steady-state formula for the case of a non-zero drift but, In the authors words (p, 427), the results "turn out to be extremely cumbersome and hard to interpet."
} 
to period $t$ at which money holdings are $M$. Thus, the present value of expected foregone earnings up to the first adjustment is:

$$
J_{1}\left(M_{0}\right)=r \int_{0}^{\infty} e^{-r t}\left\{\int_{M=0}^{\infty} M h\left(M, t \mid M_{0}, 0\right) d M\right\} d t .
$$

It is shown in Appendix A that expected foregone earnings may be written as:

$$
J_{I}\left(M_{0}\right)=M_{0}-(1-\alpha) \frac{\mu}{r}
$$

where

$$
\alpha=\exp \left\{-\frac{M_{0}}{\sigma^{2}}\left[\left(\mu^{2}+2 r \sigma^{2}\right)^{1 / 2}-\mu\right]\right\},
$$

and as may be seen, $\alpha$ depends on the various parameters of the model as well as on the optimal money holdings, $\mathrm{M}_{0}$.

We turn now to the derivation of the second component of the expected cost--the part that is incurred following the first adjustment. Let the present value of total expected cost be denoted by $G\left(M_{0}\right)$. Clearly, $G\left(M_{0}\right)$ is independent of time. ${ }^{1}$ The period at which money holdings reach zero and adjustment becomes necessary, is random. Let $\mathrm{f}\left(\mathrm{M}_{0}, t\right)$ be the probability that money holdings which at period zero were at the optimal level $M_{0}$, reached zero (the lower bound) at perlod $t$. Thus, the present value of the expected cost following the first adjustment 16:

$$
J_{2}\left(M_{0}\right)=\int_{0}^{\infty} e^{-r t}\left[C+G\left(M_{0}\right)\right] f\left(M_{0}, t\right) d t
$$

and It can be' shown that ${ }^{2}$

I The $G\left(M_{0}\right)$ function, which excludes the current "broker's fee" that is assoclated with acquiring $M_{0}$, plays the role of the yalue function of dynamic programing, It is independent of time due to the infinite horizon and the constant discount rate.

${ }^{2}$ Cox and Mller (1965, Ch. 5.7) show that a is the Laplace transform of the first passage probability of a Weiner process through a linear boundary, that is:

$$
\dot{\alpha}=\int_{0}^{\infty} e^{-r t} \mathrm{E}\left(M_{0}, t\right) d t
$$


$\left(4^{\prime}\right)$

$$
\mathrm{J}_{2}\left(\mathrm{M}_{0}\right)=\alpha\left[\mathrm{C}+\mathrm{G}\left(\mathrm{M}_{0}\right)\right]
$$

Combining the two components of the cost, $J_{I}\left(M_{0}\right)$ and $J_{2}\left(M_{0}\right)$, yields $G\left(M_{0}\right)$, the present value of total expected cost:

$$
G\left(M_{0}\right)=M_{0}-(1-\alpha) \frac{\mu}{x}+\alpha\left[C+G\left(M_{0}\right)\right]
$$

or equivalently,

(5') $G\left(M_{0}\right)=\frac{M_{0}+\alpha C}{1-\alpha}-\frac{\mu}{r}$.

Minimizing the expected cost of financlal management amounts to minfmizing $G\left(M_{0}\right)$ with respect to the optimal money stock $M_{0}$. Carrying out the minimization yields equation (6) as the necessary condition for optimality: ${ }^{1}$

$$
(1-\alpha)+\left(M_{0}+C\right) \frac{\partial \alpha}{\partial M_{0}}=0
$$

Expanding the necessary condition (6) In Taylor series (around $M_{0}$ ), Ignoring terms of third and higher order and solving for $M_{0}$, ylelds equation (7) as the optimal money holding: 2

$$
M_{0}=\sqrt{\frac{2 C \sigma^{2}}{\left(\mu^{2}+2 r \sigma^{2}\right)^{1 / 2}-\mu}} .
$$

As is evident, equation (7) satisfies the homogeneity postulate; a rise In the price level which raises $\sigma, \mathrm{C}$ and $\mu$ by a given proportion, results in an equiproportional rise in $\mathrm{M}_{0}$.

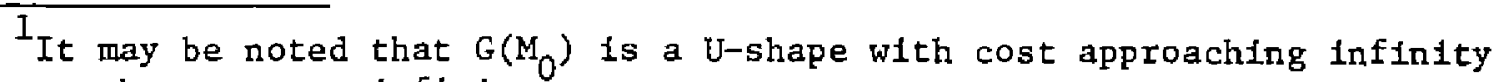
as $\mathrm{M}_{0}$ approaches zero or infinity.

${ }^{2}$ It is shown in Appendix $B$ that the approximation involved in neglecting terms of third and higher order is negligtble. Here, and in what follows, we refer to $\mathrm{M}_{0}$ as the optimal money holdings. Strictly speaking. $\mathrm{M}_{0}$ denotes the initial optimal money holdings, i.e., it denotes the magnitude of the adjustment in money holdings. If the adjustment is effected by withdrawing cash from the bank, then $M_{0}$ denotes the size of the withdrawal. 


\section{II.2 Two Specta1 Cases}

Equation (7) encompasses the various strands in the 11terature of optimal money holdings. It contains elements of the pure transactions motive that have been emphastzed in the Baumol-Tobin models (summarized by the deterministic drift $\mu$ ), along with elements of the precautionary motive ar1sing from the stochastic nature of net disbursements that have been emphasized in the M1llerOrr and Whalen rodels (sumarized by $\sigma$ ). In vlew of these contributions, it is of interest to examine the implications of two special cases. In the first case, corresponding to the Baumol-Tob in Eramework, it is assumed that the process governing net disbursements is deterministic, that is, $\sigma^{2}=0$. In the second case, corresponding to the Miller-orr and Whalen framework, it is assumed that the process governing net disbursements is stochastic without any drift, that is, $\mu=0$.

To examine the first case we expand the bracketed term in the denominator of equation ( 7 ) around $\sigma^{2}=0$ :

$$
\left(\mu^{2}+2 r \sigma^{2}\right)^{1 / 2}=\mu+\frac{1}{2} \mu^{-1} 2 r \sigma^{2}+0\left(\sigma^{4}\right)
$$

where $0\left(\sigma^{4}\right)$ denotes terms of order $\sigma^{4}$ and higher. Substituting in equation (7) yields:

$$
M_{0}=\sqrt{\frac{2 C \sigma^{2}}{\mu^{-1} r \sigma^{2}+o\left(\sigma^{4}\right)}}
$$

Taking the limit of (8) as $\sigma^{2}$ approaches zero yields:

$$
\lim _{\sigma^{2}+0} M_{0}=\sqrt{\frac{2 \overline{\mathrm{C} p}}{\mathrm{r}}} .
$$

As is evident, equation (9) is Identical with the Baumol-Tobin formulation of optimal transaction balances. In this case, when net disbursements are deterministic, the time profile of money balance has the familiar "saw-tooth" form and the 
minimum cost of financial management ylelds the familiar "square-root rule."

To examine the second special case in which $\mu=0$, we evaluate equation,

(J) at $\mu=0$ obtaining:

$$
M_{0}=\sqrt{\frac{2 C \sigma^{2}}{\left(2 \pi \sigma^{2}\right)^{I / 2}}}
$$

which can be written as:

(10 $) \quad \mathrm{M}_{0}=2^{1 / 4} \mathrm{C}^{1 / 2} \sigma^{1 / 2} \mathrm{r}^{-1 / 4}$

In this case, the elasticlties of the demand for money with respect to the cost of transactions $C$ and with respect to the standard deviation of net disbursements are $1 / 2$ and the elasticlty with respect to the rate of interest is $-1 / 4$. In the Miller-orr model (w1th lower and upper bounds) and in Whalen's model, the elasticity of the demand with respect to the cost of transactions $1 \mathrm{~s} 1 / 3$, the elasticity with respect to the standard deviation 1 s $2 / 3$, and the elasticity with respect to the rate of interest is $-1 / 3$. We turn now to a more detalled analysis of the various elasticities for the general case.

\section{3 The Elasticities of Optimal} Money Holdings

From equation (7) it can be seen that the transactions elasticity of optimal money holdings $\left(\pi_{\mathrm{M}_{0} \mu}\right)$ is:

$$
n_{M_{0} \mu}=\frac{1}{2}\left(1+\frac{2 r \sigma^{2}}{\mu^{2}}\right)^{-1 / 2} \text {. }
$$

Thus, in genera1, the transactions elasticity is positive and is smaller than 1/2;

It Increases with the volume of transactions $\mu$ and 1 decreases with the rate of Interest $r$ and with the standard deviation of net disbursements $0{ }^{1}$ It $1 s$ also

\footnotetext{
${ }^{1}$ It might be noted that the transactions elasticity approaches zero as
} the ratio $r \sigma^{2} / \mu^{2}$ approaches infinity. Thus, the range of the transactions elasticity is between zero and $1 / 2$. For attempts to introduce flexibility into the implications of the Baumol-Tobin model, see Barro (1970) and Karns: (1973). 
evident from equation (11) that, in the spectal case for which $\sigma^{2}=0$, the transactions elasticity is $1 / 2--$ the Baumol-Tobin case.

Likewise, from equation (7), the interest elasticity of optimal money holdings $\left(\eta_{M_{0}}\right)$ is:

$$
\eta_{M_{0}}=-\frac{1}{2}\left[\frac{r \sigma^{2}}{\mu^{2}+2 r \sigma^{2}-\mu\left(\mu^{2}+2 r \sigma^{2}\right)^{1 / 2}}\right] \text {, }
$$

and as may be seen, the interest elasticity 1 s negative and is smaller than $1 / 2$ (in absolute value). It may also be seen that 1 approaches $-1 / 2$ as $\sigma^{2}$ approaches zero--the Baumol-Tobin case. ${ }^{1}$ For a positive $\sigma^{2}$, the interest elasticity varies witi the volume of transactions $\mu$. It approaches $-1 / 2$ when $\mu$ approaches infinfty and, as shown In equation $\left(10^{\circ}\right)$, it approaches $-1 / 4$ as $\mu$ approaches zero. ${ }^{2}$

It can be shown that the elasticlty of optimal money holdings with respect to the standard deviation of net disbursements $\left(n_{M_{0} \sigma}\right)$ is related to the corresponding elasticity with respect to the rate of interest according to:

$$
\eta_{M_{0} \sigma}=1+2 \eta_{M_{0}} r
$$

The relationship between the two elasticities in equation (13) seems to be robust. For example, it is also satisfied in the Miller-orr and Whalen models of optimal money holdings.

III. The Payments Period and the Probability of Adjustment

In this section we analyze (1) the determinants of the payments perlod--

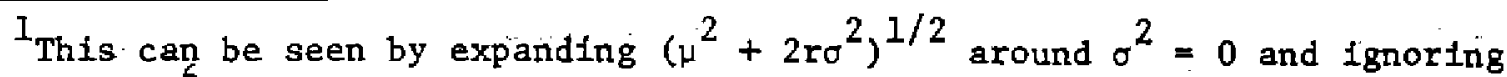
terms of order $\sigma^{6}$ and higher; alternatively, expanding around $r=0$ and Ignoring. terms of $\mathrm{r}^{3}$ and higher ylelds the same result.

$\therefore \quad 2$ The specificafion in equation (7) and the implied transactions and interest elasticities Include $\sigma^{2}$ as one of the parameters whose omission in empirical estimation may lead to a specification bias. For example, to the extent that income (and thus transactions) and $\sigma^{2}$ are positively correlated, estimates of the demand for money will result in upward blased estimates of the transactions elasticlty. 
the length of time intervals between consecutive adjustments, and ( 11 ) the determinants of the probability that money holdings reach the lower bound and thereby make adjustment necessary.

In a fully deterministic model of the Baumol-Tobin varlety, the length of the payments period is $M_{0} / \mu--$ the ratio of the optimal money stock to the $\mathrm{ateady}$ flow of expenditures per unit of time. ${ }^{1}$ In a stochastic framework, the length of the payments period is characterized by a distribution whose mean is equal, by definition, to the ratio of $\mathrm{M}_{0}$ to the mean flow of net disbursements. Since in our case the mean flow of net disbursements is $\mu$, it follows that the nean payments period is $\mathrm{M}_{0} / \mu$. We turn now to a more detalled analysis of the distribution of the payments period.

In Section II. I we denoted the probability that money holdings, which at period zero were at the optimal level, reached zero at period $t$, by $f\left(M_{0}, t\right)$. It is clear that the distxibution of the length of the payments perfod 1s governed by the function $f\left(M_{0}, t\right)$. It is shown in Cox and Miller (1965, Ch. 5.7) that the density is:

$$
f\left(M_{0}, t\right)=\frac{M_{0}}{\sqrt{2 \pi} \sigma t^{3 / 2}} \exp \left\{\frac{-\left(M_{0}-\mu t\right)^{2}}{2 \sigma^{2} t}-\right\},
$$

with a mean $M_{0} / \mu$ and a variance $M_{0} \sigma^{2} / 2 \mu^{3}$. To find the mode of the distribution we differentiate equation (14) with respect to time, equate to zero, and solve for the mode. The resulting (unfque) mode 1s:

$$
\frac{M_{0}}{\mu}\left\{\left[1+\left(\frac{3 \sigma^{2}}{2 M_{0} \mu}\right)^{2}\right]^{1 / 2}-\frac{3 \sigma^{2}}{2 M_{0}^{\mu}}\right\} .
$$

As may be seen, the mode of the distribution is smaller than the mean ${ }^{2}$ and 1 coincides

\footnotetext{
${ }^{I_{F o r}}$ an interesting analysis of the optimal payments perfod see Barro (1970).

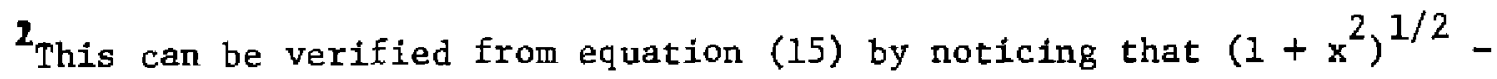
$x<1$
} 
with the mean when $\sigma=0$ (the Baumol-Tobin case). These properties of the distribution of the payments period are summarized in figure 1.

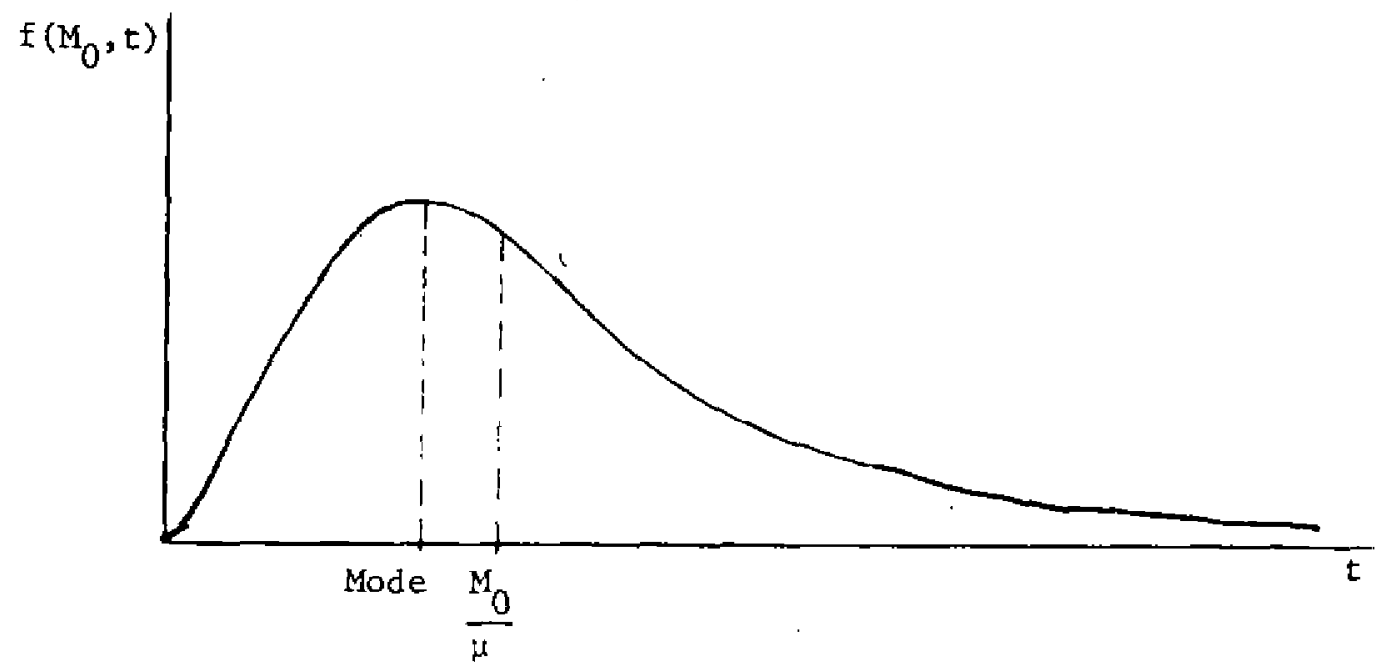

Figure 1

In the special case for which $\mu$ approaches zero, it can be shown, using equation (15), that the mode of the distribution of the payments period is $\mathrm{M}_{0}^{2} / 3 \sigma^{2} . \underline{1}$ Substituting equation (10) for $\mathrm{M}_{0}$, yields $c \sqrt{2 / r} / 3 \sigma$ as the mode of the distribution. Thus, In this case, a higher rate of interest and a higher gtandard deviation of net disbursements reduce the (mode of the distribution of the) length

I This can be shown by rewriting equation (15) as

$$
\left(1 / 2 \mu^{2}\right)\left[-x+\left(x^{2}+4 \mu^{2} M_{0}^{2}\right)^{1 / 2}\right]
$$

where $x \equiv 3 \sigma^{2}$. Expanding $\left(x^{2}+4 \mu^{2} M_{0}^{2}\right)^{1 / 2}$ in a Taylor series ylelds:

$$
x+(1 / 2) x^{-1} 4 M_{0}^{2} \mu^{2}+O\left(\mu^{4}\right)
$$

where $O\left(\mu^{4}\right)$ denotes terms in $\mu^{4}$ and higher. Substituting back yields:

$$
\left(1 / 2 \mu^{2}\right)\left[\mathrm{x}^{-1} 2 \mathrm{M}_{0}^{2} \mu^{2}+0\left(\mu^{4}\right)\right] \text {. }
$$

By taking the limit as $\mu^{2}$ approaches zero, we obtain $\mathrm{M}_{0}^{2} / 3 \sigma^{2}$ as the value of the mode. 
of the payments period while a higher cost of adjustment ("broker's fee") raises the mode.

The above analysis can also be used for determining the probability of adjustment. Let the probabilfty that adjustment will occur prior to perlod $t$ be denoted by $F\left(M_{0}, t\right)$. Using the previous notations it is clear that

$$
F\left(M_{0}, t\right)=\int_{0}^{t} f\left(M_{0}, s\right) d s,
$$

and as is shown in Cox and Miller (1965, Ch. 5.7), this probability can be written explicitly as:

$$
F\left(M_{0}, t\right)=1-N\left[\frac{M_{0}-\mu t}{\sigma t^{1 / 2}}\right]+\mathbb{N}\left[\frac{-M_{0}-\mu t}{\sigma t^{1 / 2}}\right] \exp \left[\frac{2 \mu M_{0}}{\sigma^{2}}\right] .
$$

In the special case for which $\mu=0$, equation (17) becomes

$$
F\left(M_{0}, t\right)=2\left(1-N\left[\frac{M_{0}}{\sigma t^{1 / 2}}\right]\right)
$$

where

$$
N(x)=\frac{1}{\sqrt{2 \pi}} \int_{-\infty}^{x} e^{-x^{2} / 2} d x
$$

As is clear,

$$
\lim _{t \rightarrow \infty} F\left(M_{0}, t\right)=1 \text { since } N(0)=1 / 2
$$

To analyze the determinants of the probability of adjustment in this case, we substitute equation (10) for $\mathrm{M}_{0}$ in equation (18) to yield:

$$
F\left(M_{0}, t\right)=2\left(1-N\left[\left(\frac{C ; / 2}{r^{1 / 2} \sigma t}\right){ }^{1 / 2}\right]\right)
$$

Thus, higher values of $r, \sigma$ and $t$ increase the probability that adjustment will be necessary while a higher cost of adjustment decreases that probability. The effect of $\sigma$ is of some interest since a higher value of o raises optimal money holdings which operate to reduce the probability of adjustment (since from equation (18) 
$\left.\partial F(\cdot) / \partial M_{0}<0\right)$. Equation (19) reveals that the induced rise in the optimal money stock will not offset completely the direct effect of the rise in $\sigma$ on the probability of adjustment.

IV. The Steady-State Distribution and a Steady-State Approach

In this section we derfve the steady-state distribution of money holdings and provide a complete characterization of this distribution. We then adopt a steady-state approach and use these results for an alternative derivation of optimal money holdings.

\section{IV.1 The Steady-State Distribution}

In deriving the steady-state distribution we start with some notations. Let the steady-state probability denstty of money holdings be denoted by the function $\phi(M)$. In Section II.I we denoted by $H\left(M, t \mid M_{0}, 0\right)$ the probability that money holdings, which at period zero were at the optimal level $\mathrm{M}_{0}$, had not reached zero prior to period $t$ at which money holdings were $M$. In what follows, it will be convenient to simplify the notation and denote this probability by $\theta(M \mid t)$. We further denote by $g(t)$ the probability that adjustment took place exactly $t$ periods ago. We saw in Section III that the mean of the length of the paymento period is $M_{0} / \mu$. As is known from renewal theory, In the steady state, the probability $g(t)$ approaches a constant $g *$ which is equal to the inverse of the payments period: 1

$$
g^{*}=\frac{\mu}{M_{0}} .
$$

${ }^{1}$ See for example Feller (1971, Ch. XI). In this context [g*dt] can be interpreted as the probability that the process (which has been in existence forever) will cross the zero boundary during the time interval $[t, t+d t]$. 
Finally, let $\psi(t \mid M)$ be the probability that the previous adjustment occurred exactly $t$ perfods ago given that current money holdings are M. Using Bayes' Theorem, the steady-state distribution can be expressed as:

$$
\phi(M)=\frac{\theta(M \mid t) g^{*}}{\psi(t \mid M)},
$$

and substituting equation (20) for g* yields:

$$
\phi(M)=\frac{\mu}{M_{0}} \frac{\theta(M \mid t)}{\psi(t \mid M)} .
$$

The function $\phi(M)$ pertains to the steady-state and thus $1 \mathrm{t}$ is Independent of time. If follows that the ratio $\theta(M \mid t) / \psi(t \mid M)$ in equation (22) must also be independent of time and, therefore, we can use in (22) the ratio of the integrals of .$\phi\left(^{\cdot}\right)$ and $\psi(\cdot)$ with respect to time:

(22') $\phi(M)=\frac{\mu}{M_{0}} \frac{0}{\int_{0}^{\infty} \psi(t \mid M) d t}$.

$$
f^{\infty} \theta(M \mid t) d t
$$

We note, however, that the probabllity that the prevlous adjustment occurred more than $t$ periods ago approaches zero as $t$ approaches Infinfty and, therefore,

$$
\int_{0}^{\infty} \psi(t \mid M) d t=1
$$

Using this fact in (22') ylelds the expression for the steady-state distribution:

$$
\phi(M)=\frac{\mu}{M_{0}} \int_{0}^{\infty} \theta(M \mid t) d t .
$$

By integrating the right hand side of equation (23) (using some of the expressions from Appendix A), the steady-state distribution can be written as: 1

(24) $\phi(M)=\left\{\begin{array}{l}\frac{1}{M_{0}}\left[1-\exp \left(-2 M \mu / \sigma^{2}\right)\right] \text { for } 0 \leq M \leq M_{0} \\ \frac{1}{M_{0}}\left[\exp \left(-2\left(M-M_{0}\right) \mu / \sigma^{2}\right)-\exp \left(-2 M \mu / \sigma^{2}\right)\right] \text { for } M>M_{0} .\end{array}\right.$

It can be verlfied that average money holdings in the steady-state are:

$$
\text { It can be verified that } \int_{0}^{\infty} \phi(M) d M=1 \text {, as it should. }
$$




$$
E(M) \equiv \int_{0}^{\infty} M \phi(M) d M=\frac{1}{2}\left(M_{0}+\frac{\sigma^{2}}{\mu}\right)
$$

and the vartance of money holdings in the steady state is:

$$
\operatorname{Var}(M) \equiv \frac{M_{0}^{2}}{12}+\frac{\sigma^{4}}{4 \mu^{2}} \text {. }
$$

In the special case for which $\sigma=0$, the constant flow of expenditures $1 s \mu$, and the mean of the distribution of steady state money holdings is $\mathrm{M}_{0} / 2--$ the Baumol-Tobin case. Finally, it should be noted that in the speclal case for which $\mu=0$, the steady-state distribution does not extst. ${ }^{1}$ The various characteristics of the steady-state probability density of money holdings for alternative values of $\sigma$ are described in Figure 2; as may be seen, In the spec1al case for which $\sigma=0$, the distribution becomes uniform.

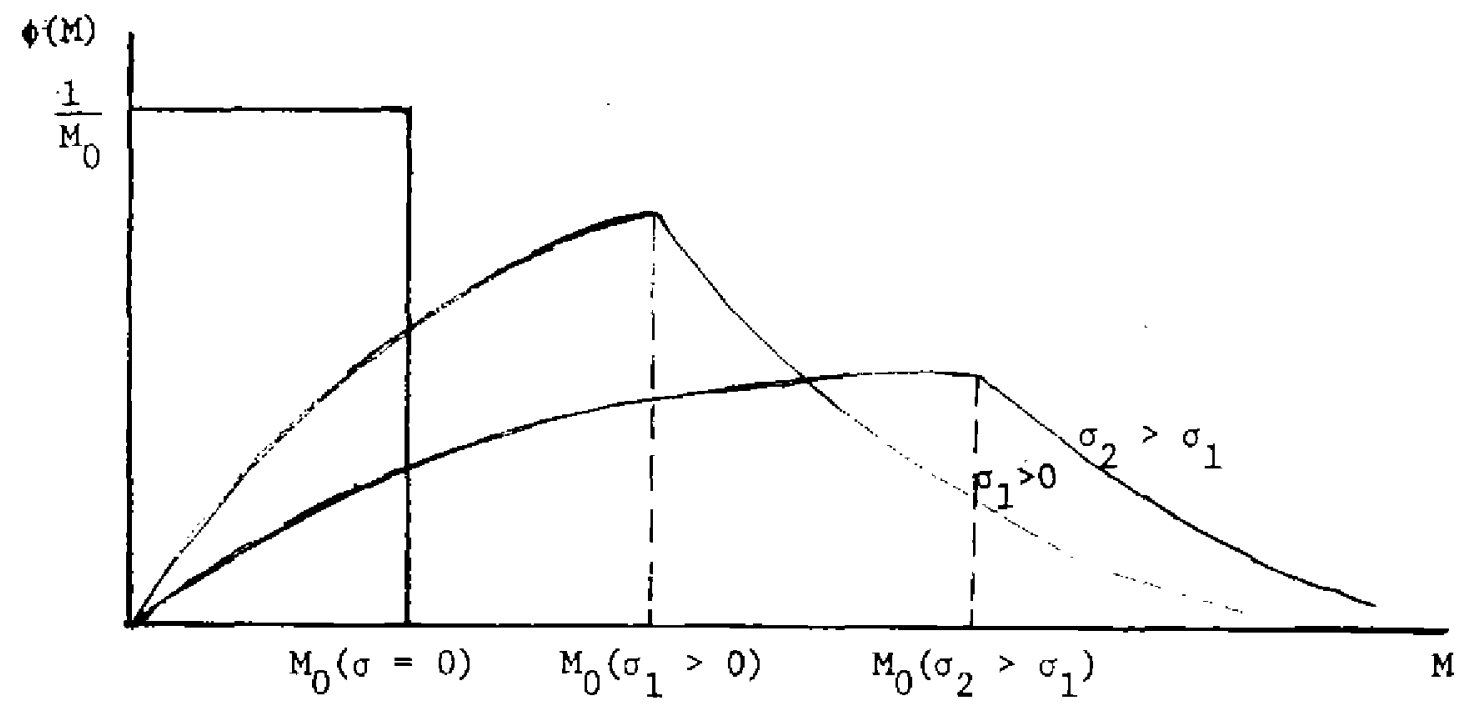

F1gure 2

IV. 2 An Alternative Derlvation: The Steady-State Approach

In deriving the optimal money holdings $\mathrm{M}_{0}$, we followed the procedure of minimizing the present value of financial management. In contrast, an alternative

$1_{\text {As Indicated fn. }} 1$, p. 4, the steady-state distribution in the Miller-Orr model existssince they assume lower and upper bounds. 
methodology which has been adopted by Miller and orr (1966) and investigated by Arrow, Karlin and Scarf (1958), is to compute the optimum from the solution obtained by minimizing the steady-state cost function. Arrow, et a1 indicated that the two alternative approaches may not yleld identical results and, that the justification for the use of the approximation involved in mintmizing the steady-state cost function 1 s on grounds of simplicity. In order to compare the two alternative methods, we turn to the steady-state approach and derive the optimal money holdings that are implied by minimizing the steady-state cost function.

The expected cost of financlal management per unit of time in the steadystate is composed of the expected "broker's fee" and the expected foregone earnings per unit of time. The expected number of adjustments per unt of time in the steady state is $g^{*}$ (the steady-state renewal density) which, from equation (20), equals $\mu / \mathrm{M}_{0}$-the 1nverse of the mean payments perfod. Thus, the expected steady-state "broker's fee" per urit of time is $\mathrm{Cg}^{*}$. In addition, average money holdings in the steady state are $E(M)$, and foregone earnings per unit of time are IE(M). Thus, using equations (20) and (25), total costs per untt of time in the steady state are:

$$
\mathrm{Cg} * \mathrm{rE}(\mathrm{M})=\frac{\mathrm{C} \mu}{\mathrm{M}_{0}}+\frac{\mathrm{r}}{2}\left(\mathrm{M}_{0}+\frac{\sigma^{2}}{\mu}\right) .
$$

Mnimizing this cost function with respect to $M_{0}$ and solving for the optimal money holdings yleld:

$$
\mathrm{M}_{0}=\sqrt{\frac{2 \mathrm{C \mu}}{\mathrm{r}}}
$$

which is identical to equaton (9), and which corresponds to the solution for the special case analyzed by Baumol and Tobin. 
As is clear, the solution in equation (28) differs fundamentally from the general solution in equation (7) which was obtalned by minimizing the present value of the cost of financlal management. The most important difference is that the solution obtained by the steady-state approach does not depend on the value of the variance $\sigma^{2}$ which, in turn, plays a key role in the general solution. It seets that, in this case, the adoption of a steady-state approach results in an elimination of the effects of the stochastic characteristics of the process governing money holdings. Thus, following the steady-state approach, results in a fundamentally different interpretation of the determinants of optimal money holdings. While the solution in equation (7) may be interpreted as contalning elements which pertain to both transactions and precautionary motives for holding money, the solution In equation (28) contafins only the deterministic transaction motive. Obviously, In the speclal case for which o $=0$, the two solutions coincide. ${ }^{1}$

The comparison of the two solutions in equation (7) and (28) also raises a methodological question concerning the appropriateness of approximating optimal adjustment pollcies by using a steady-state approach. The steady-state approach is, of course, much simpler but unless one knows the true solution (as in our case), the cost of obtaining simplicity cannot be assessed.

\section{An Empirical Application to Internat Lona1 Reserves}

In this section we apply the model to an analysis of the holdings of International reserves. In the empirfcal application we assume that the holdings of International reserves are governed by the stochastic process in equation (1)

$1_{\text {As }}$ is indicated by Arrow et al (1958, p. 35) the two methods yield identical results when the rate of interest is zero. It implies that the difference between the two methods arises due to the discounting involved in the present value computation. A comparison of equation (8) and (24) with a zero rate of interest illustrates the point. 
with no drift $(\mu=0)$. Thus, we assume that on average the balance of payments is balanced. I our assumption that adjustment occurs when reserves reach a lower bound rather than an upper bound, seems to be especially appropriate for the analysis of international reserves. The asymmetry in the division of the burden of adjustment is well known; typlcally, adjustment is forced on the deficit countries rather than on the surplus countries.

The previous analysis implies that, for the special case of no drift, the optimal level of reserves (following an adjustment) is $R_{0}$ (equation (10'), Section II) :

$$
R_{0}=2^{1 / 4} C^{1 / 2}{ }^{1 / 2} r^{-1 / 4}
$$

Since in this case the steady-state distribution does not exist, we have assumed in the empirical analysis that the observed data correspond to countries which have adjusted recently. We have pooled cross-section and time series (annual) data for 22 developed countries over five years (1971-75) and have estimated the parameters of equation $(30)::^{2}$

$$
\ln R=b_{0}+b_{1} \ln \sigma+b_{2} \ln r+u
$$

where $u$ denotes an error term. The predictions of the model are that $b_{1}=.50$ and that $b_{2}=-.25$.

For the purpose of estimation, International reserves are defined as the sum of gold, Spectal Drawing Rights, forelgn exchange, and reserve positton at the

${ }^{1}$ For analysis emphasizing the stochastic properties of the time series of international reserves, see Archibald and Richmond (1971), Heller (1966) and Kenen and Yudin (1965); for analyses of international reserves in the context of inventory models, see Makin (1974) and olivera (1969).

2 The classification of countries as "developed" is based on the International Monetary Fund. A11 data sources are from the IFS tape, obtained from the International Monetary Fund. We are indebted to Cralg Hakkio for assistance in the estimations. 
Fund. The variablitity measure, $\sigma$, is computed for each year as the standard error (over the previous 15 years) of the trend-adjusted annual changes in the stock of international reserves. The rate of interest is the government bond yleld or (depending on avallabllity) the discount rate (except for Japan for which we use the call-money rate).

In estimating equation (30) we allowed for a separate constant term for each country. The least-squares parameter estimates are reported in equation (31) and the various country-speciflc constant terms are reported in Table 1 with standard errors in parentheses below each coefficlent.

$$
\begin{aligned}
\ln \mathrm{R} & =\mathrm{b}_{0}+\underset{(.110)}{.505} \ln \sigma-\underset{(.149)}{.279} \ln \mathrm{r} \\
\mathrm{R}^{2} & =.975, \mathrm{n}=110, \text { s.e. }=234
\end{aligned}
$$

As may be seen, for that perfod, the estimated elasticities of reserve holdings with respect to $\sigma$ and $r$ are extremely close to the predictions of the theoretical model. It is noted, however, that these results should be viewed with caution since they might be sensitive to the omission of a scale variable from the specification of equation (30). Furthermore, it has been shown in Frenkel (1978) that the function which includes a scale varlable but which excludes the rate of interest, underwent a structural change by the end of 1972 and, therefore, the pooling of data from the period prior to 1973 with data from the subsequent period might not have been appropriate. To examine the fmplicatlons of this possibility, we added a scale variable (meausred by the level of 1mports, IM) and reestimated the resulting equation over the period 1963-72 $(n=198)$. The resulting estimates are reported in equation (31'); the country-specific constant terms (which are all signfficant) are not reported here.

$$
\ln \dot{R}=b_{0}+\underset{(.063)}{.676} \ln \sigma-\underset{(.141)}{.233} \ln r+\underset{(.102)}{.352} \ln \text { IM. }
$$


TABLE 1

IEAST-SQUARES ESTIMATES OF COUNTRY-SPECIFIC

CONSTANT TERMS: 1971-75

(standard errors in parentheses)

\begin{tabular}{llll}
\hline United Kingdom & 5.621 & Japan & 6.084 \\
Austria & $(.731)$ & & $(.787)$ \\
& 5.882 & Finland & 4.731 \\
Belgium & $(.511)$ & & $(.456)$ \\
& 6.010 & Greece & 4.931 \\
Denmark & $(.562)$ & & $(.472)$ \\
& 5.008 & Iceland & 3.420 \\
France & $(.498)$ & & $(.298)$ \\
& 6.115 & Ireland & 5.361 \\
Germany & $(.703)$ & & $(.459)$ \\
& 6.783 & Portugal & 5.489 \\
Italy & $(.780)$ & & $(.514)$ \\
& 6.076 & Spain & 5.853 \\
Netherlands & $(.622)$ & & $(.627)$ \\
& 6.195 & Turkey & 5.096 \\
Norway & $(.584)$ & & $(.528)$ \\
& 5.564 & Australia & 5.536 \\
Sweden & $(.457)$ & & $(.655)$ \\
Switzerland & 5.294 & New Zealand & 4.522 \\
& $(.544)$ & & $(.471)$ \\
& 6.420 & South Africa & 4.742 \\
& $(.603)$ & & $(.553)$ \\
\hline
\end{tabular}

Note: These are the constant terms corresponding to equation (31) in the text. 
We conclude this section by stating that, on the whole, the empirical results are consistent with the model. However, since the estimated parameters seem to be somewhat sensitive to the specification and to the choice of the time period, they should be interpreted only as fllustrative. ${ }^{1}$

VI. Concluding Remarks

In this paper we developed a stochastic framework for the analysis of transactions and precautionary demand for money and we attempted to integrate some aspects of previous contributions by Baumol (1952), Tobin (1956) and Miller and Orr (1966). We derived formally the solution for optimal money holdings as a function of the rate of Interest, the mean rate of net disbursements, the cost of portfolio adjustment, and the varlance of the stochastic procesa governing net disbursements. We also analyzed the determinants of the optimal length of time elapsing between two consecutive portfolfo adjustments. We then followed the more traditional approach and analyzed the steady-state distribution of money holdings and derived the optimal money stock that is implied by the steady-state approach. A comparison of the two solutions illustrated that the two approaches may yield solutions which differ significantly from each other. This comparison led to the methodological question concerning the appropriateness of approximating optimal adjustment policies by following the steady-state approach. We concluded the analysis by applying the model to an emplrical examination of countries' holdings of International reserves. The analysis of the demand for International reserves illustrated some of the potentially useful applications of the mode1.

\footnotetext{
I This statement is based on our own experimentation with different specifications as well as on other studies. As is well known, other studies using different specifications and different time periods have encountered difficulties in incorporating the rate of interest in the estimated reserve equation. For references and details, see Frenkel (1978).
} 
APPENDIX

Mathematical Derivations

In part $A$ of this Appendix we derive equation ( $\left.3^{\prime}\right)$ in the text and in part $B$ we show that the approximation involved in the derivation of equation (7) introduces a negligible error.

\section{$\underline{\text { Part A }}$}

We have assumed that money holdings are governed by the stochastic equation:

$$
\text { (A.1) } \quad d M(t)=-\mu d t+\sigma d W(t) ; \quad M(0)=M_{0} \text {. }
$$

In order to correspond with Cox and Miller's framework (1965, Ch. 5.7) In which the first passage is for a process whtch starts at zero and goes through a positive boundary, we perform the following transformations. Define

(A.2) $\hat{d M}(t)=\mu d t-\sigma d W(t) ; M(0)=-M_{0}$.

and

(A.3) $d x(t)=\mu d t-\sigma d W(t) ; x(0)=0$.

Thus, $\hat{M}(t)$ is the mirror image of $M(t)$ in the negative half-plane, and $x(t)=$ $\hat{\mathrm{M}}(\mathrm{t})+\mathrm{M}_{0}$.

Let $\tilde{h}\left(M, t \mid-M_{0}, 0\right)$ be the probability that $\hat{M}(t)$ (defined by equation (A.2)), w111 not reach zero before period $t$, and that $M(t)=M$. Then equation (3) in the text becomes

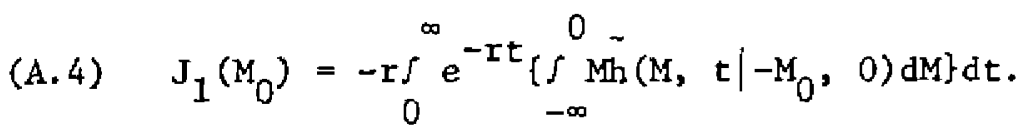

Analogously, in order to shift the origin so as to conform with Cox and Miller's framework, let $h *\left(x, t\left\{0, M_{0}\right)\right.$ be the probability that $x(t)$ will not reach the boundary $M_{0}$ before $t$, and that $x(t)=x$. Since $x(t)=\hat{M}(t)+M_{0}$, the relat1onship 
between $h *(\cdot)$ and $\vec{h}(\cdot)$ is:

(A. 5) $\quad h *\left(x, t \mid 0, M_{0}\right)=\tilde{h}\left(x-M_{0}, t \mid-M_{0}, 0\right)$.

In order to use the function $h^{*}(\cdot)$, we change the variables in (A.4) by subst1tuting $x=M+M_{0}$ :

(A. 6) $\left.J_{1}\left(M_{0}\right)=-r \int_{0}^{\infty} e^{-r t_{\{}} \int_{-\infty}^{M_{0}}\left(x-M_{0}\right) \tilde{h}\left(x-M_{0}, t \mid-M_{0}, 0\right) d x\right\} d t$,

and using (A.5) in (A.6) results in:

(A.7) $\quad J_{1}\left(M_{0}\right)=-r \int e_{0}^{\infty} e_{-\infty}^{-r t}\left\{\delta_{-\infty}^{M}\left(x-M_{0}\right) h *\left(x, t \mid 0, M_{0}\right) d x\right\} d t$.

Decomposing (A.7) Into expressions which involve $M_{0}$ and expression which involve $x$, yields:

(A.8) $\left.\quad J_{1}\left(M_{0}\right)=I_{0} \int_{0}^{\infty} e^{-I t} \int_{-\infty}^{M_{0}} h \star\left(x, t \mid 0, M_{0}\right) d x\right\} d t-$

$$
\left.-r \int_{0}^{\infty} e^{-r t_{\{f}} M_{-\infty}^{0} x h^{*} *\left(x, t \mid 0, M_{0}\right) d x\right\} d t
$$

Let $f\left(M_{0}, t\right)$ be the probability that $x(t)$ will reach $M_{0}$ for the first time at t. To simplify the notation, we will refer to this probability as $f(t)$. Thus, $f(t)$ Is also the probability that $M(t)$ reaches zero for the first time at $t$; therefore, the probability that the process will reach zero prior to $t$ is:

$$
F(t) \equiv \int_{0}^{t} f(s) d s
$$

It follows that the probability of not reaching zero prior to period $t$ 1s:

$$
\int_{-\infty}^{\mathrm{M}} \mathrm{h} *\left(\mathrm{x}, \mathrm{t} \mid 0, \mathrm{M}_{0}\right) \mathrm{dx}=1-F(\mathrm{t})
$$

Using this result to evaluate the first integral in (A.8) yielda: 
(A. 8. 1) $\int_{0}^{\infty} r e^{-r t}[1-F(t)] d t=\left[-e^{-r t}(1-F(t))\right]_{0}^{\infty}-\int_{0}^{\infty} e^{-r t} f(t) d t$.

Cox and Miller (1965, Ch. 5.7) show that:

$$
\begin{aligned}
& \int_{0}^{\infty} \mathrm{e}^{-r t}(f) d t=\alpha, \text { where } \\
& \alpha=\exp \left\{-\frac{M_{0}}{\sigma^{2}}\left[\left(\mu^{2}+2 r \sigma^{2}\right)^{1 / 2}-\mu\right] ;\right.
\end{aligned}
$$

substituting in (A.8.i) yields:

(A.8.i1)

$$
\int_{0}^{\infty} r e^{-r t}\left\{\int_{-\infty}^{M_{0}} h *\left(x, t \mid 0, M_{0}\right) d x\right\} d t=1-\alpha .
$$

We turn now to evaluate the second Integral in (A.8). Cox and Miller (1965, Ch. 5.7) show that

$h *\left(x, t \mid 0, M_{0}\right)=\frac{1}{\sqrt{2 \pi} \sigma t^{1 / 2}}\left[\exp \left\{\frac{-(x-\mu t)^{2}}{2 \sigma^{2} t}\right\}-\exp \left[\frac{2 \mu M_{0}}{\sigma^{2}}-\frac{\left(x-2 M_{0}-\mu t\right)^{2}}{2 \sigma^{2} t}\right\}\right]$.

Substituting into (A.8) and integrating by parts yields

(A. 9) $J_{1}\left(M_{0}\right)=M_{0}+\int_{0}^{\infty} e^{-r t} D(t) d t$

where

$$
D(t)=N\left[\frac{-M_{0}-\mu t}{\sigma t^{1 / 2}}\right] \exp \left\{\frac{2 \mu M_{0}}{\sigma^{2}}\right\}-N\left[\frac{M_{0}-\mu t}{\sigma t^{1 / 2}}\right]
$$

and where

$$
N(x) \equiv \int_{-\infty}^{x}(2 \pi)^{-1} e^{-z^{2} / 2} d z
$$

Integrating by parts ylelds equation (3') in the text. 
$\underline{\text { Part B }}$

The necessary condition for optimization is:

$$
(1-\alpha)+\left(M_{0}+C\right) \frac{\partial \alpha}{\partial M_{0}}=0
$$

Multiplying through by $\beta \equiv 1 / \alpha$ and noting that $2 \alpha / \partial M_{0}=-k \alpha$ where $\alpha$ is defined by equation $\left(3^{\prime}\right)$ in the text and where $k=\frac{1}{\sigma^{2}}\left[\left(\mu^{2}+2 r \sigma^{2}\right)^{1 / 2}-\mu\right]>0$, (B.1) becomes:

$\left(B .1^{\prime}\right)-k\left(M_{0}+C\right)+\beta-1=0$

Taylor's Theorem with remainder Implies that for some constant $\lambda(0 \leq \lambda \leq 1)$, the term $\beta$ in $\left(B .1^{\prime}\right)$ can be expanded as:

(B. 2) $B=\beta(0)+\frac{\partial \beta(0)}{\partial M_{0}} M_{0}+\frac{1}{2} \frac{\partial^{2} B(0)}{\partial M_{0}^{2}} M^{2}+\frac{1}{6} \frac{\partial^{3} B\left(\lambda M_{0}\right)}{\partial M_{0}^{3}} M_{0}^{3}$.

Substituting a quadratic expansion of $\beta$ (without the third order term) into (B.1') yields:

(B. 3) $-k\left(M_{0}+C\right)+\frac{\partial \beta(0)}{\partial M_{0}} M_{0}+\frac{1}{2} \frac{\partial^{2} B(0)}{\partial M_{0}^{2}} M_{0}^{2}=0$

(since $B(0)=1$ ) and the solution for $M_{0}$ is given in equation (7) In the text. Using (B.1') and (B.2), the true solution for $M_{0}$, which we denote by $\bar{M}$, satisfles equation (B.4):

(B. 4) $-k(\bar{M}+C)+\frac{\partial \beta(0)}{\partial M_{0}} \bar{M}+\frac{1}{2} \frac{\partial^{2} \beta(0)}{\partial M_{0}^{2}} \bar{M}^{2}+\frac{1}{6} \frac{\partial^{3} \beta(\lambda \bar{M})}{\partial M_{0}^{3}} \bar{M}^{3}=0$.

To determine the extent of the error involved in the approximation, we subtract (B.2) from (B.4) and cancel terms to obtain:

(B.5) $\quad \frac{1}{2}\left(\bar{M}^{2}-M_{0}^{2}\right)+\frac{1}{6} k \exp \{\lambda \bar{M} k\} \bar{M}^{3}=0$ 
since

$$
\frac{\partial \beta(0)}{\partial M_{0}}=k, \frac{\partial^{2} \beta(0)}{\partial M_{0}^{2}}=k^{2} \text {, and } \frac{\partial^{3} \beta(\lambda \bar{M})}{\partial M_{0}^{3}}=k^{3} \exp \{\lambda \bar{M} k\}
$$

Equation (B.5) implies that

$$
\frac{M_{0}^{2}-\bar{M}^{2}}{\bar{M}^{2}}=\frac{k}{3} \exp (\lambda \bar{M} k] \bar{M} \geq 0
$$

and, therefore, the approxinate solution $M_{0}$, exceeds the true solution $\vec{M}$.

Substituting $\mathrm{M}_{0}$ for $\overline{\mathrm{M}}$ ylelds the following inequalitles:

$$
0 \leq \frac{M_{0}^{2}-\bar{M}^{2}}{\bar{M}^{2}} \leq \frac{k}{3} \exp \left\{\lambda M_{0} k\right\} M_{0} \leq \frac{k}{3} e^{M_{0} k} M_{0}
$$

where the last inequality follows since $0 \leq \lambda \leq 1$. Since equation ( 7 ) in the text states that:

$$
M_{0}=(2 \mathrm{C})^{1 / 2} \mathrm{k}^{-1 / 2}
$$

(A.12) becomes

$$
\text { (B. } \left.6^{\prime}\right) \quad 0 \leq \frac{M_{0}^{2}-\bar{M}^{2}}{M} \leq \frac{(2 k C)^{1 / 2}}{3} \exp \left\{(2 \mathrm{kC})^{1 / 2}\right\} \text {. }
$$

Thus, the relative error is negligible if $\mathrm{kC}$ is negligible. From equation (7) In the text, $k=2 \mathrm{C} / \mathrm{M}_{0}^{2}$ and, therefore,

$$
\mathrm{kC}=2\left(\frac{\mathrm{C}}{\mathrm{M}_{0}}\right)^{2} \leq 2\left(\frac{\mathrm{C}}{\mathrm{M}}\right)^{2}
$$

where $C / \bar{M}$ is the "broker's fee" divided by the true optimum $\bar{M}$. As a practicaI matter, for any reasonable onter of magnitudes, the ratio $C / \bar{M}$ must be a very small fraction and 1 ts square must be negligible and so 1 s $\mathrm{kC}$. Thus, the solution for the optimum that is given by equation (7) is a good approximation to the true solution. 


\section{REFERENCES}

Archibald, G. C. and Richmond, J. "On the Theory of Forelgn Exchange Reserve Requirements." The Review of Economic Studies 38, no. 2 (Apr11 1971): $245-63$.

Arrow, K. J.; Karlin, S. and Scarf, H. Studies in the Mathematical Theory of Inventory and Production. Stanford: Stanford Unfversfty Press, 1958.

Barro, Robert J. "Inflation, the Payment Perfod and the Demand for Money." Journal of Political Economy 78, no. 6 (November/December 1970): 1228-63.

Baumol, William J. "The Transactions Demand for Cash: An Inventory Theoretical Approach." Quarterly Journal of Economics 66, no. 4 (November 1952): 545-56.

Cox, R. D. and Miller, H.D. The Theory of Stochast1c Processes. London: Methuen Ltd., 1965.

Feller, W. An Introduction to Probabllity and Its Application, Vol. II, 2nd, ed. New York: Wiley, 1971.

Fischer, Stanley. "The Demand for Index Bonds." Journal of Polftical Economy 83, no. 3 (June 1975): 509-34.

Frenke1, Jacob A. "International Reserves: Pegged Exchange Ratea and Managed Float." In Brunner, K. and Meltzer, A.H. (eds.) Economlc Policles in Open Economies, Vol. 9 of the Camegle-Rochester Conference Series on Public Policy, a Supplementary Serles to the Journal of Monetary Economics (July 1978).

Heller, Robert H. "Optlmal International Reserves." Economic Journal 76 (June 1966): 296-311.

Karni, Ed1. "The Transactions Demand for Cash: Incorporating the Value of Time tnto the Inventory Approach." Journal of Political Economy 81, no. 5 (September/October, 1973): 1216-25.

Kenen, Peter B. and Yudin, Elinor B. "The Demand for International Reserves." Review of Economics and Statist1cs 47 (August 1965): 242-50.

Makin, John H. "Exchange Rate Flextbility and the Demand for International Reserves." Weltwirtschaftliches Archiv 110, no. 2 (1974): 229-43.

Miller, Merton H. and Orr, Daniel. "A Model of the Demand for Money by Ffrms." Quarterly Journal of Economics 80, no. 3 (August 1966): 413-35.

Olivera, Julio H. G. "A Note on the Optimal Rate of Growth of International Reserves." Journal of Political Economy 77, no. 2 (March/April 1969): 245-48. 
Olivera, Julio H.G. "The Square-Root Law of Precautionary Reserves." Journal of Political Economy 79, no. 5 (September/October): 1095-1104.

Orr, Daniel. Cash Management and the Demand for Money. New York: Praeger, 1970.

Patinkin, Don. Money Interest and Prices, 2nd ed. New York: Harper \& Row, 1965.

Tobin, James. "The Interest-Elasticity of Transactions Demand for Cagh." Review of Economics and Statistics 38, no. 3 (August 1956): 241-7.

Tsiang, S. C. "The Precautionary Demand for Money: An Inventory Theoretical Analysis." Journal of Polittcal Economy 77, no. 1 (January/February, 1969): 99-117.

Whalen, Edward L. "A Rationalization of the Precautionary Demand for Cash." Quarterly Journal of Economics 80, no. 2 (May 1966): 314-24. 